\title{
An easy-to-use index of ecological integrity for prioritizing freshwater sites and for assessing habitat quality
}

John P. Simaika, andd Michael J. Samways

Department of Conservation Ecology and Entomology, and Centre for Invasion Biology, Faculty of AgriSciences, University of Stellenbosch, Private Bag X1, Matieland, 7602, South Africa

\begin{abstract}
Prioritizing and assessing the condition of sites for conservation action requires robust and ergonomic methodological tools. We focus here on prioritizing freshwater sites using two promising biodiversity indices, the Dragonfly Biotic Index (DBI) and Average Taxonomic Distinctness (AvTD). The AvTD had no significant association with either species richness or endemism. In contrast, the DBI was highly significantly associated with species richness and endemism, although the strengths of the associations were weak. These associations are related to how the sub-indices in the DBI are weighted, and how species are distributed geographically. Additionally, the DBI was found to be very useful for site selection based on its ability to measure ecological integrity, combined with level of threat, at multiple spatial scales. The AvTD was found to be useful principally for regional use. As the DBI is a low-cost, easy-to-use method, it has the additional use as a method for assessing habitat quality and recovery in restoration programs. The DBI operates at the species level, and is therefore highly sensitive to habitat condition and has great potential for environmental assessment and monitoring freshwater biodiversity and quality. Practical, worked examples of river restoration are given here. In view of the ease and versatility by which the DBI can be employed, we recommend its testing and possible integration into freshwater management and conservation schemes elsewhere in the world.
\end{abstract}

\section{Keywords:}

Conservation, Prioritization, Assessment, Freshwater, Catchments, Odonata, Taxonomic distinctness, Dragonfly Biotic Index .

\section{Introduction}

Site prioritization for conservation action, such as the setting aside of reserves and delineation of hotspots, is usually based on biodiversity measures such as species richness, abundance, complementarity, taxonomic and functional diversity, diversity at different scales (i.e. $\alpha, \beta$, and $\gamma$ ), and indices that combine some of the above measures (Magurran 2004). The most commonly used diversity measure in ecology is species richness (Jennings et al. 2008; Fleishman et al. 2006; Magurran 2004). However, there are five problems with diversity measures based on species counts alone (Warwick and Clarke 2001; Fleishman et al. 2006): Firstly, species richness is heavily dependent on sampling effort, and is therefore highly sensitive to sample size and non-comparable across studies involving unknown or differing degrees of sampling effort. Secondly, species richness does not directly reflect phylogenetic diversity. Thirdly, although observed species richness measures can be compared across sites, which are strictly controlled by sampling design, the values of species richness cannot be compared against an absolute standard. Fourthly, the response of species richness to environmental degradation is not monotonic. Indeed, Wilkinson (1999) notes that under 
moderate levels of disturbance, species richness may increase. Fifthly, species richness will differ markedly with different habitat types.

An additional problem with species richness is that the measure is scale-dependent (Jennings et al. 2008). Some studies of higher taxa found that areas of high endemism do not correspond with those of high species richness at regional (Prendergast et al. 1993) nor at global scales (Orme et al. 2005). However, other studies, using different resolutions, at the regional (Graham and Hijmans 2006) and global (Lamoreux et al. 2006) scale did find a correlation. Given two assemblages with identical numbers of species and equivalent patterns of species abundance, but differing in the diversity of taxa to which they belong, the most taxonomically varied assemblage will be the more diverse (Clarke and Warwick 2001).

In response to these findings, Average Taxonomic Distinctness (AvTD) has been proposed as a biodiversity measure (Warwick and Clarke 1995; Clarke and Warwick 1998, 2001). It calculates the average taxonomic distance between any two species chosen at random from a sample. In contrast to other diversity measures, AVTD can be used in situations where sampling is uncontrolled, unknown or unequal, and where data are nominal, i.e. species are present or absent. Indeed, use of simple species lists has the advantage of ensuring that no one species can dominate contributions to the index (Clarke and Warwick 1998, 2001). Measures of taxonomic diversity can be used in conjunction with species richness and rarity scores in the context of conservation (Virolainen et al. 1998). Already, taxonomic distance has gained impetus in environmental assessment (Heino et al. 2007; Ellingsen et al. 2005; Mouillot et al. 2005; Clarke and Warwick 1998).

The Dragonfly Biotic Index (DBI) is also a biodiversity measure, but based on a blend of expert knowledge of the focal species and quantitative assessment (Simaika and Samways 2008a). The DBI is based on the widely recognized potential of Odonata as indicator species (Chovanec 2000), although to date the index has been used only for measuring habitat recovery (Samways and Taylor 2004). This is an extension of the fact that odonates can be used as indicators of freshwater health (Oertli 2008), ecological integrity (Smith et al. 2007; Chovanec and Waringer 2001), and global climate change (Ott 2008).

We investigate here the value and use of the AvTD and DBI: (1) for measuring ecological integrity (i.e.: species composition of habitats), (2) for prioritizing sites for protection, and, (3) discuss the use of the DBI in freshwater quality assessments such as for restoration.

\section{Methods}

\section{Background on the Dragonfly Biotic Index}

As in the case of the AVTD, the DBI relies on species presence/absence data. The DBI is comprised of three sub-indices: a species relative geographic distribution, threat status based on IUCN Categories and Criteria (IUCN 2001), and species sensitivity to habitat disturbance (Table 1) (Simaika and Samways 2008a). Each sub-value ranges from 0 to 3 . The sum of the sub-values for any one species is the standard DBI score, which can range from 0 to 9 . The standard DBI for all known South African odonate species is given in Samways (2008). 
Table 1

The sub-indices of the Dragonfly Biotic Index (DBI) range from 0 to 3

\begin{tabular}{|c|c|c|c|}
\hline \multirow{2}{*}{ Score } & \multicolumn{3}{|l|}{ Sub-indices } \\
\hline & Distribution & Threat & Sensitivity \\
\hline 0 & $\begin{array}{l}\text { Very common throughout South } \\
\text { Africa and southern Africa }\end{array}$ & LC; GS & $\begin{array}{l}\text { Not sensitive; little affected by } \\
\text { habitat disturbance and may even } \\
\text { benefit from habitat change due to } \\
\text { alien plants; may thrive in } \\
\text { artificial waterbodies }\end{array}$ \\
\hline 1 & $\begin{array}{l}\text { Localized across a wide area in South } \\
\text { Africa, and localized or common in } \\
\text { southern Africa; or very common in 1- } \\
3 \text { provinces and localized or common } \\
\text { in southern Africa }\end{array}$ & $\begin{array}{l}\text { NT; GS or } \\
\text { VU; NS }\end{array}$ & $\begin{array}{l}\text { Low sensitivity to habitat change } \\
\text { from alien plants; may occur } \\
\text { commonly in artificial } \\
\text { waterbodies }\end{array}$ \\
\hline 2 & $\begin{array}{l}\text { National endemic confined to } 3 \text { or } \\
\text { more provinces; or widespread in } \\
\text { southern Africa but marignal and very } \\
\text { rare in South Africa }\end{array}$ & $\begin{array}{l}\text { VU; GS or } \\
\text { CR; NS or } \\
\text { EN; NS }\end{array}$ & $\begin{array}{l}\text { Medium sensitivity to habitat } \\
\text { disturbance such as from alien } \\
\text { plants and bank disturbance; may } \\
\text { have been recorded in artificial } \\
\text { waterbodies }\end{array}$ \\
\hline 3 & $\begin{array}{l}\text { Endemic or near-endemic and } \\
\text { confined to only } 1 \text { or } 2 \text { Provinces }\end{array}$ & $\begin{array}{l}\text { CR; GS or } \\
\text { EN; GS }\end{array}$ & $\begin{array}{l}\text { Extremely sensitive to habitat } \\
\text { change from alien plants; only } \\
\text { occurs in undisturbed natural } \\
\text { habitat }\end{array}$ \\
\hline
\end{tabular}

It is based on the three sub-indices relating to geographical distribution, level of threat, and sensitivity to habitat change, with particular reference to invasive alien riparian trees. The DBI is the sum of the scores for the three sub-indices, and ranges from 0 to 9 . A common, widespread, not-threatened and highly tolerant (of disturbance) species would score $0(0+0+0)$, while a highly range-restricted, threatened and sensitive species would score $9(3+3+3)$

Abbreviations: IUCN species threat status (IUCN 2001): LC least concern, NT near threatened, VU vulnerable, CE critically endangered, EN endangered, GS global status, and NS national status (Table modified from Simaika and Samways 2008a)

To arrive at a DBI score per site, we divided the total of all the standard DBIs by the total number of species. The range of values for the DBI per site will therefore fall between 0 and 9 .

\section{Database development}

Biogeographic information from South Africa (including Lesotho and Swaziland) was used here. This area is unique in that such information is not only available to potential users worldwide, via the internet (SANBI 2008), but that many taxa, including the Odonata, are well sampled. A spatialrelational database was constructed from records of adult dragonfly and damselfly collections and sightings. The database consists of a merger between Samways' database of collections and sightings (from 1988 to present) and a database of Pinhey's $(1984,1985)$ records. Additional records came from insect collections housed at the Iziko Museum (Cape Town), Albany Museum (Grahamstown), Northern Flagship Institution (Pretoria), National Museum (Bloemfontein) and National Insect Collection (Pretoria). Museum visits included verification of old records and identification of new specimens accessioned since 1984. Additional records came from new collection effort, with special emphasis on endemic species sampling, during the field seasons from 2005 to 2008 in the western and eastern Cape. These new records extend the known geographical range of the endemic Red Listed Ecchlorolestes peringueyi and E. nylephtha (Simaika and Samways 2008b), and discoveries of the two new species Syncordulia legator and S. serendipator (Dijkstra et al. 2007). From the resultant database, species distribution maps were constructed using both ArcView GIS 3.2a and ArcGIS 9.2 
(Environmental Survey Research Institute 1999, 2006). The quaternary catchments map of South Africa was used for distribution mapping (SANBI 2008).

\section{Statistical analysis}

To ensure that equal sampling effort was compared, and that statistical analyses could be done using the presence/absence data from the compiled South African Odonata database, a minimum of ten species per catchment was admitted for analysis (Bob Clarke, Primer-E, pers. comm. 2008). This decision was made after comparison of analyses with a minimum of three and then five species. Analysis with lower species numbers (a minimum of three and five species) confirmed that a minimum sampling effort of ten species is required for meaningful analysis.

To allow for easy comparison of AvTD and the DBI, quaternary catchments were grouped into larger primary catchment areas, called zones (Fig. 1). A count of sampled quaternary catchments in each primary catchment zone is presented in Table 2 . These primary catchment zones are equivalent to the existing river regions used by Schulze et al. (2006) and earlier by Midgley et al. (1994), and their convention was not altered here. Primary areas that were under-represented were clustered into larger zones, where possible. Clustering was not an arbitrary process, but made by a careful, repeated elimination process in Primer 5 (Clarke and Warwick 2001). First, species occurrence in each quaternary catchment was averaged by the primary catchment, using the AVERAGE function in Primer 5. The averages were then standardized and square-root transformed in a Bray-Curtis similarity matrix. Using the similarity matrix, a CLUSTER dendrogram, clustered by group average, was produced (Fig. 2). Average taxonomic distinctness was calculated using PRIMER 5. Analysis of variance (ANOVA) was run both on AvTD and DBI data using SPSS 13 (SPSS Inc. 2004). The Kolmogorov-Smirnov test of normality and Levene test for homogeneity of variances were employed using SPSS 13.0 The tests determined the non-normality and un-equal variance of the index data. Therefore, the Brown-Forsythe test was used as an alternative to analysis of variance. Tamhane post hoc test was used to determine which zones differed significantly in biodiversity. To determine whether the biodiversity indices are correlated, a Spearman Rank correlation was used in SPSS 13, as the data were non-normally distributed. Recovery scores for examples used in the application of the $\mathrm{DBI}$, were calculated by dividing the value before restoration by the value after restoration, and expressing this as a percentage. This was done using species richness, giving the Species Recovery Score (SRS), and the DBI, giving the Dragonfly Reovery Score.

\section{Results}

The AvTD described per primary catchment zone is visualized in Fig. 3. High AvTD scores have a widespread distribution, running along the Great Escarpment of South Africa, starting with the coastal belt in the Cape, high in endemism, from the west to the east Coast 


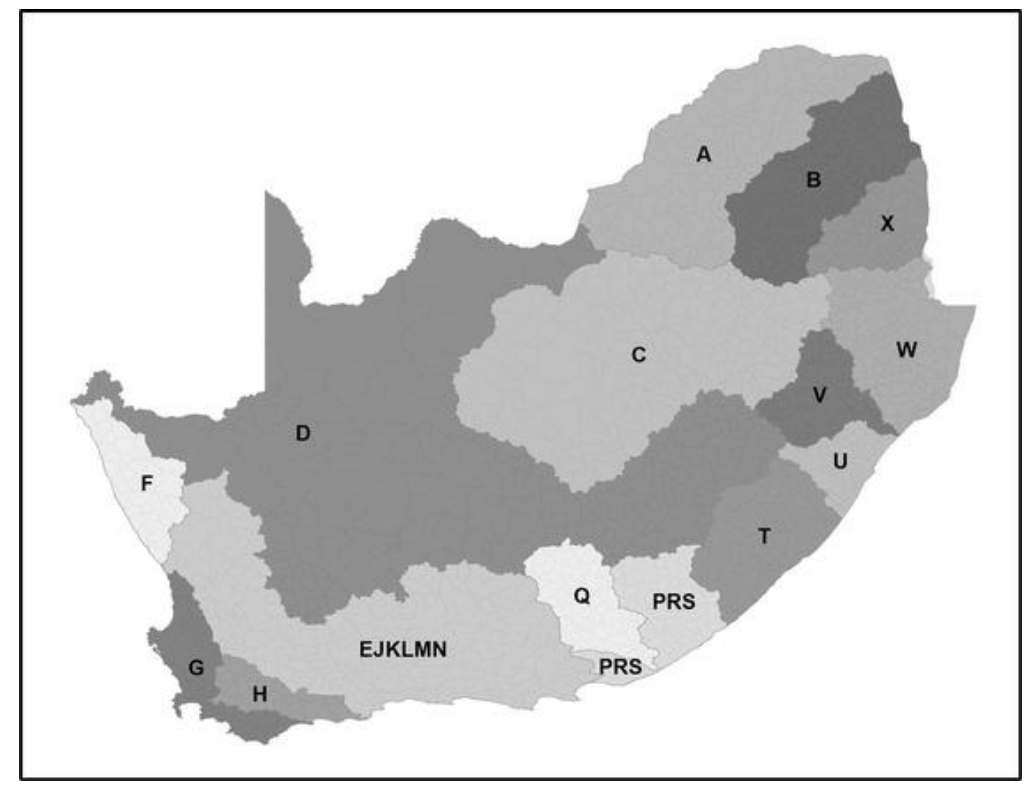

Fig. 1

Primary catchment zones of South Africa. Highlighted quaternary catchments (strong gray outlines) were used in the study comparing the biodiversity indices. The Buffels and Fish river systems (F and Q) were not included in the analyses, due to insufficient sampling effort in the areas. Abbreviations are as follows: A (Limpopo); B (Olifants); C (Vaal); D (Orange); EJKLMN: E (Olifants), J (Gourits), K (Keurboom/Storm/Krom), L (Gamtoos), M (Swartkops), N (Sundays); G

(Berg/Bot/Potberg), H (Breede); PRS: P (Bushmans), R (Keiskamma), S (Kei); T (Mzimvubu); U (Mkomazi); V (Tugela); W (Mfolozi/Pongola); and, X (Komati/Crocodile)

Table 2

Count of sampled quaternary catchments in each primary catchment zone

\begin{tabular}{|l|l|l|}
\hline Zone & Primary catchment & Polygon count \\
\hline A & Limpopo & 34 \\
\hline B & Olifants & 23 \\
\hline C & Vaal & 7 \\
\hline D & Orange & 4 \\
\hline EJKLMN & $\begin{array}{l}\text { Olifants/Gourits/Keurboom/Storms/Krom/Gam } \\
\text { toos/Swartkops/Sundays }\end{array}$ & 15 \\
\hline G & Berg/Bot/Potberg & 11 \\
\hline H & Breede & 11 \\
\hline PRS & Bushmans/Fish/Keiskamma/Kei & 9 \\
\hline T & Mzimvubu & 8 \\
\hline U & Mkomazi & 18 \\
\hline V & Tugela & 16 \\
\hline W & Mfolozi/Pongola & 31 \\
\hline X & Komati/Crocodile & 26 \\
\hline Total & & 213 \\
\hline
\end{tabular}




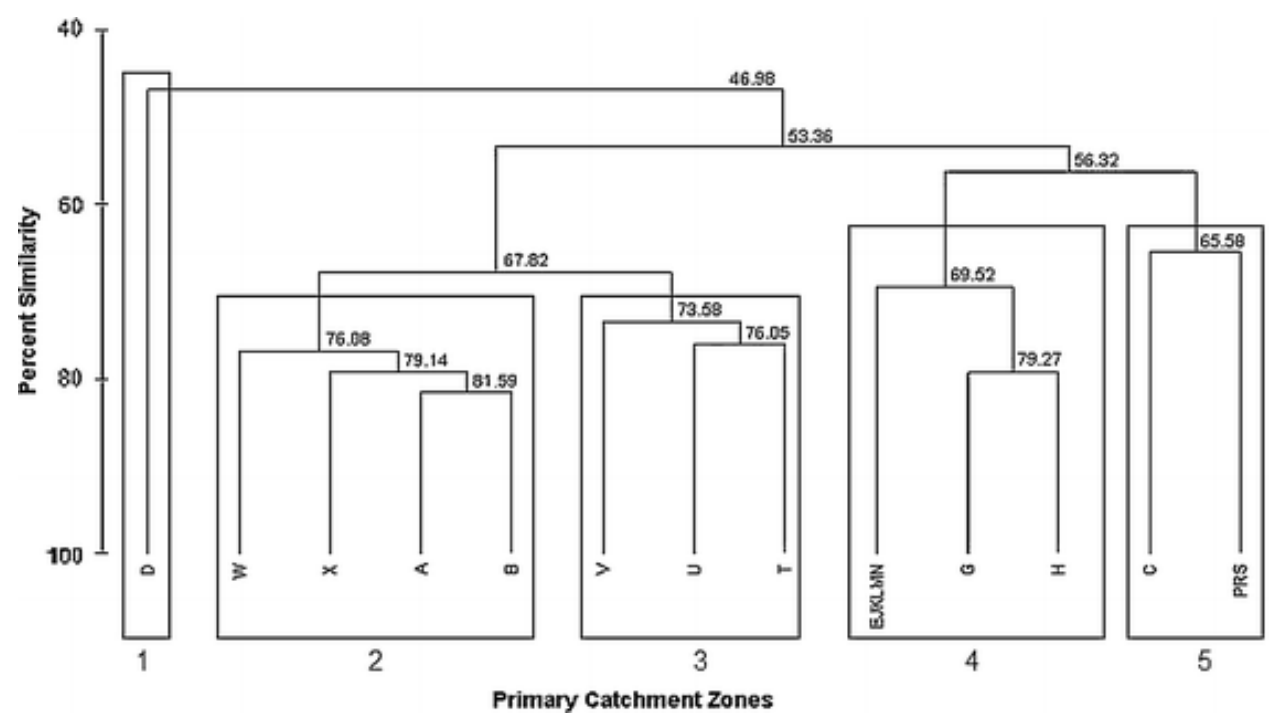

Fig. 2

Cluster graph of the primary catchment zones. Percent similarities are given for each junction. Abbreviations for catchment zones are as follows: A (Limpopo), B (Olifants), C (Vaal), D (Orange), EJKLMN

(Olifants/Gourits/Keurboom/Storm/Krom/Gamtoos/Swartkops/Sundays), G (Berg/Bot/Potberg), H (Breede), PRS

(Bushmans/Keiskamma/Kei), T (Mzimvubu), U (Mkomazi), V (Tugela), W, (Mfolozi/Pongola) and X (Komati/Crocodile)

(G, H, EJKLMN and PRS), and further inland into the Highveld (V) and KwaZulu-Natal (W, X) northwards, to the species rich lowveld region of Mpumalanga (A, B).

The analysis of variance (ANOVA) test revealed that there are significant differences between zones $(F=5.14, d f=12, P<0.01)$. The Tamhane post hoc test determined which catchment zones were responsible for these differences. Catchment zone $A$ differs significantly from EJKLMN $(P<0.01), G$ $(P<0.00), H(P<0.00)$, PRS $(P<0.00)$ and $V(P<0.00)$; zone $B$ from $H(P<0.04)$ and $P R S(P<0.00)$; zones EJKLMN and $G$ from zone $A$; zone $H$ from zones $A, B$, and $W(P<0.01)$; zone PRS from zone $A$, $B, W(P<0.00)$ and $X(P<0.00)$; zone $V$ from $A$; zone; zone $W$ from $H$ and $P R S$; and, zone $X$ from zone $P R S$. Zones $C, D, T$ and $U$ did not differ significantly from any other zone.

Comparison of Figs. 3 and 4 reveals that the means of the zones, while significantly different, are overall high. Thus, there are many catchments with high AvTD scores.

\section{Dragonfly Biotic Index}

Visualization of the DBI scores for South African odonate assemblages is presented in Fig. 5. A very small proportion of catchments have a high DBI score. These are all restricted in the Cape region, in primary zones $\mathrm{G}$ and $\mathrm{H}$ in the south-west, and EJKLMN in the south-east Cape. Most of the mediumhigh DBI scores are distributed south of the Great Escarpment, from the south-west Cape ( $G$ and $H)$, along the south east coastal belt (PRS, $\mathrm{U}, \mathrm{W}$ ). Inland medium scores are also found in zone EJKLMN in the Cape; D in the Karoo; T in the Transkei; V in KwaZulu-Natal, and X, B and A in Mpumalanga.

The analysis of variance (ANOVA) test revealed that there are significant differences between the means of the DBIs of the primary zones $(F=8.937, d f=12, P<0.01)$ (Fig. 6$)$. The Tamhane post hoc test determined which means of the primary catchment zone were responsible for the observed differences. The mean DBls of primary catchment zone A, B, C, 


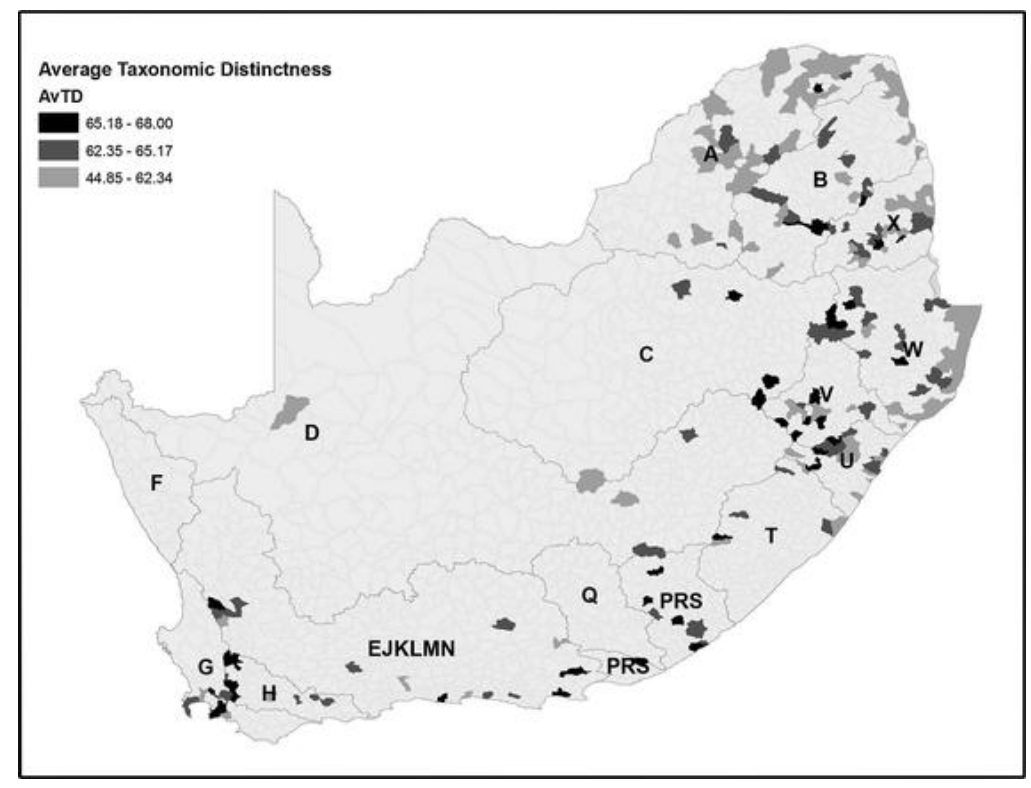

Fig. 3

Average Taxonomic Distinctness (AvTD) of assemblages of South African Odonata per quaternary catchment. Light gray catchments indicate low AvTD value, dark gray catchments medium value, and black catchments high value

$\mathrm{H}, \mathrm{V}$, and $\mathrm{W}$ are significantly different from at least one other catchment zone. Catchment zone $\mathrm{A}$ differs significantly from zone $H(P<0.02)$ and $W(P<0.01)$; zone $B$ differs significantly from zone $H$ $(P<0.04)$; zone $C$ also differs significantly from zone $H(P<0.03)$; zone $H$ differs significantly from zones $\mathrm{A}, \mathrm{B}, \mathrm{C}$ and $\mathrm{V})$; zone $\mathrm{V}$ is significantly different from zone $\mathrm{H}(\mathrm{P}<0.04)$; and zone $\mathrm{W}$ is significantly different from zone $A(P<0.01)$.

Comparison of Figs. 5 and 6 confirms that the highest DBI means are in catchment zones $\mathrm{G}, \mathrm{H}$, EJKLMN and PRS. In zone EJKLMN, primary catchments $\mathrm{K}$ and $\mathrm{M}$ are most responsible for the high means. The mean of PRS is high overall.

\section{Comparison of AvTD to DBI}

Two-tailed Spearman's rank correlation found a weak but highly significant positive correlation between AvTD and DBI $\left(r_{s}=0.400, n=213, P<0.01\right)$. The AvTD showed no association with either species richness $\left(r_{s}=-0.091, n=213, P<0.188\right)$ or endemism $\left(r_{s}=0.151, n=50, P<0.294\right)$. The $D B I$ was found to be highly significantly correlated with species richness $\left(r_{s}=0.209, n=213, P<0.01\right)$ and with endemism $\left(r_{s}=0.448, n=50, P<0.01\right)$, yet the association of the DBI with species richness is very weak, and weak for endemism. High DBI scores are localized in the Cape region (zones $G$ and $H$ ). High AvTD scores have a wider distribution particularly catchments in zones $G, H$ and PRS, and include zone $V$ in the north-east region, poor in endemics (Figs. 3-6). High scoring AvTD catchments are also within the species rich zones, A, B and X. Catchments in zones A, B and X score either low or medium DBI. 


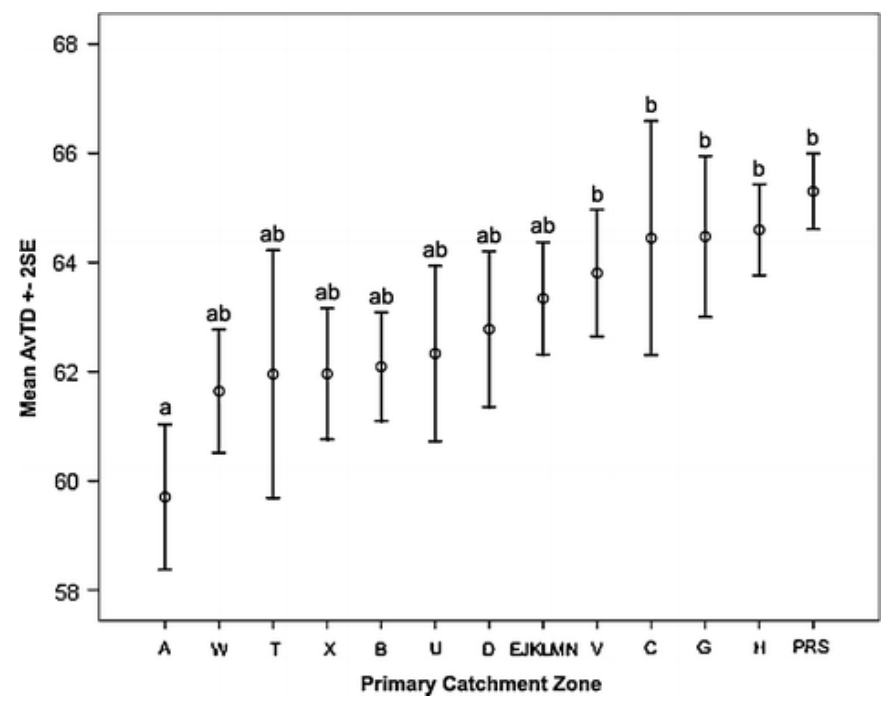

Fig. 4

Mean Average Taxonomic Distinctness (AvTD) per primary catchment zone. An analysis of variance (ANOVA) determined that zones are significantly different $(F=5.14, d f=12, P=0.0001)$. Catchment zones fall into three groups: $a(z o n e A) ; a b$ (zones B, D, EJKLMN, T, U, W and X); b (zones C, G, H, PRS, and V). Error bars represent standard error (SE) \pm 2

\section{Practical application of the Dragonfly Biotic Index}

Table 3 shows ten examples where dragonfly assemblage composition was recorded before and after restoration, achieved through removal of invasive alien trees which were shading out the naturally sunny habitats. The species are recorded as a percentage ratio (the SRS) of the number of species after restoration compared with the number prior to restoration. The recovery is also given in terms of the percentage ratio (the Dragonfly Recovery Score, DRS) of the total DBI after, compared with, prior to restoration. In all cases, both the SRS and the DRS are above $100 \%$, illustrating an increase in both number of species and in total DBI following restoration. Figure 7 shows the SRSs and the DRSs for the ten sites overlaid on a map of levels of endemism. The very high DRS values are associated with high levels of endemism, illustrating the great effectiveness of the remediation on the irreplaceable, endemic fauna. As level of endemism decreases while species richness increases, reaching the highest species richness but lowest endemism at site J, the DBI decreases in proportion to the SRS. The DBI thus has strong conservation value in that it emphasizes the threatened, narrowrange and sensitive species, and their recovery when restoration is undertaken.

\section{Discussion}

A practical index for prioritizing sites or for assessing success of conservation action must be easy to use and provide reliable, repeatable results (McGeoch 2007). Ideally, it should also operate at the species, rather than higher, taxonomic level, so as to be sensitive to the various subtle characteristics of, and changes in, the habitats (Smith et al. 2007). 


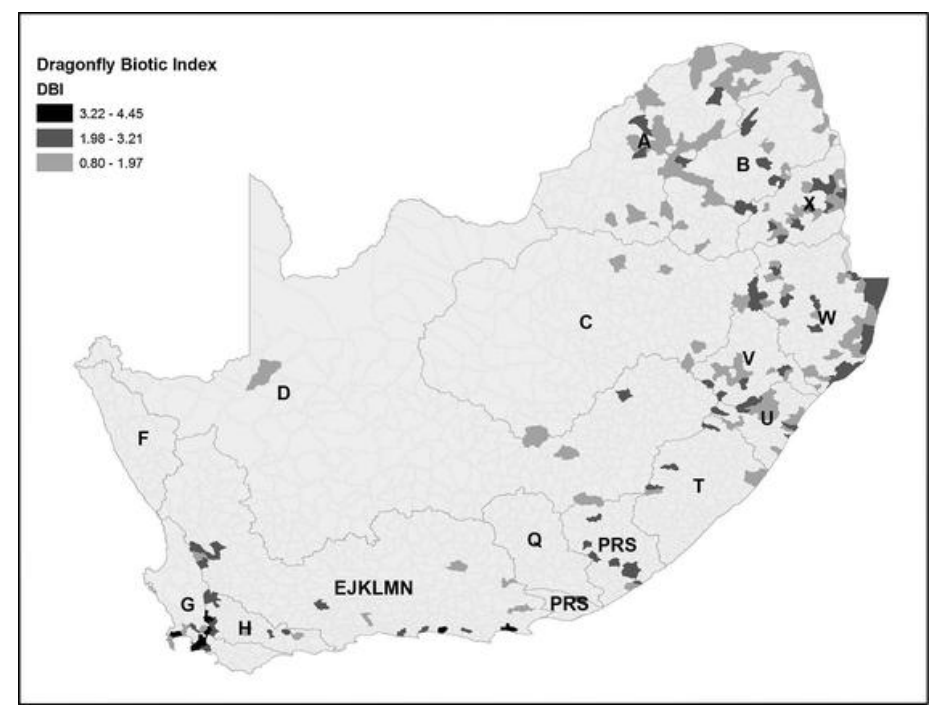

Fig. 5

Dragonfly Biotic Index scores of assemblages of assemblages of South African Odonata per quaternary catchment. Light gray catchments indicate low DBI value, dark gray catchments medium value, and black catchments high value

Many biodiversity measurements have fallen short of the ideal because they have consisted of simple counts of the numbers of species (species richness), an observation voiced by many (Jennings 2008; Price et al. 1999). Researchers have thus suggested that aggregate biodiversity levels are more important in identifying priority sites (Dinerstein and Wikramanayake 1993; Pressey et al. 1993), or alternatively, a measure of the species' identities (Jennings et al. 2008; Clarke and Warwick 2001). Therefore, it was appropriate here to test the validity of two biodiversity indices for prioritizing freshwater sites: the DBI and the AvTD.

\section{Comparison of biodiversity indices}

There was a weak but significant relationship between the AvTD and the DBI. Both indices are based on presence/absence records. Yet, these indices are very different, in that the first is based solely on weighted taxonomic relatedness (Clarke and Warwick 2001), while the latter is based on weighted geographic distribution, conservation status and sensitivity to disturbance (Simaika and Samways 2008a).

The DBI is based on a mixture of objective science and expert opinion, and gives more weight to geographically restricted, Red Listed and disturbance-sensitive species, than to any other species. Its main thrust lies in identifying species of global conservation concern. In other words, the DBI gives priority to rare and endemic Red Listed species. In South Africa, these occur, as do many other taxa, mainly in the south-west Cape and eastern Cape, regions characterized by endemic Corduliidae and Synlestidae (Figs. 5, 6). The remaining areas, particularly the north-east, are dominated by a species rich Afro-tropical element. 


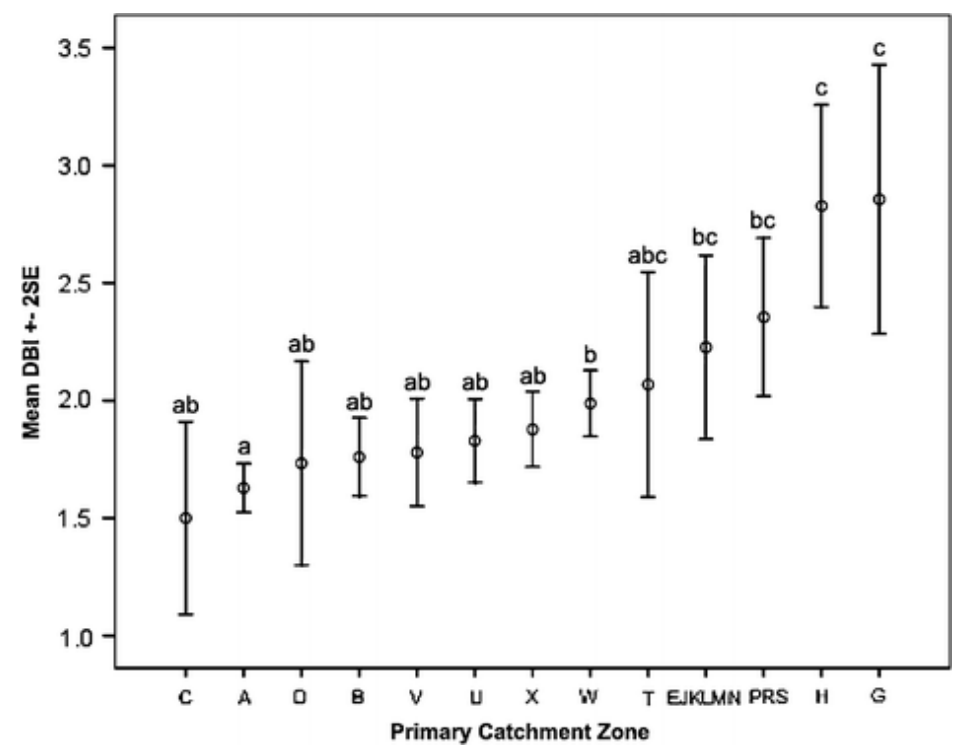

Fig. 6

Error plot of mean Dragonfly Biotic Index (DBI) per primary catchment zone. An analysis of variance (ANOVA) determined significant differences $D B I$ means of between catchments $(F=8.937, \mathrm{df}=12, \mathrm{P}=0.0001)$. Primary catchment zones fall into six larger groups, a (zone A); ab (zones B, C, D, U, V, X); abc (zone T); b (zone W); bc (zones EJKLMN, PRS); and c (zones G, H). Error bars represent standard error $(\mathrm{SE}) \pm 2$

In contrast to the DBI, the AVTD is sensitive to the taxonomic relatedness of species. It is based on the intuitive principle that an assemblage of distantly related species is more diverse than an assemblage of closely related species (Warwick and Clarke 2001). In each assemblage, the AvTD tracks this principle throughout the country from the south-west to the north-east. High AvTD values were found to have a widespread distribution, along the Great Escarpment of South Africa, starting with the coastal belt in the Cape, high in endemism, from the west to the east coast, and farther inland into the Highveld and KwaZulu-Natal northwards, to the species rich lowveld region of Mpumalanga.

This is where there appears to be the greatest difference between the AvTD and DBI. There are far fewer endemics in the north-east, and the DBI reflects this quite clearly. The DBI was found to be highly significantly associated with species richness, although the strength of the association was very weak or non-existent. The DBI was more strongly correlated with endemism than with species richness, although also a weak correlation. The AvTD in contrast was not found to have any significant association with either species richness or endemism.

The reason the DBI may be very weakly, although highly significantly, associated with species richness, is that it is intrinsically dependent on how the sub-indices in the DBI are weighted, and distributed. For example, a species assemblage of only ten highly sensitive and threatened Cape endemic odonates at a site in the Cape floristic region may score an average (i.e. score per site) DBI of seven, while at a site in the species rich region of KwaZulu-Natal, an assemblage of 25 widespread Afro-tropical species may only score an average DBI of two. 
Table 3

Changes in dragonfly species richness and Dragonfly Biotic Index (DBI) values following removal of invasive alien riparian trees

\begin{tabular}{|c|c|c|c|c|c|c|c|c|}
\hline \multirow{2}{*}{ Site } & \multicolumn{2}{|c|}{ Before } & \multicolumn{2}{|c|}{ After } & \multirow{2}{*}{\begin{tabular}{|l} 
Species recovery \\
Score (\%)
\end{tabular}} & \multirow{2}{*}{$\begin{array}{l}\text { Dragonfly recovery } \\
\text { Score (\%) }\end{array}$} & \multirow{2}{*}{ Co-ordinates } & \multirow{2}{*}{ Reference } \\
\hline & $\mathbf{S}$ & Total DBI & $\mathbf{S}$ & Total DBI & & & & \\
\hline A & 5 & 8 & 11 & 48 & 220 & 600 & $33 \div 59^{\prime} \mathrm{S}, 18 \div 24^{\prime} \mathrm{E}$ & Simaika and Samways (2008) \\
\hline B & 7 & 23 & 16 & 85 & 229 & 370 & $33 \div 35^{\prime} S, 19 \div 08^{\prime} E$ & Simaika and Samways (2008) \\
\hline C & 7 & 19 & 15 & 72 & 214 & 379 & $33 \div 57^{\prime} \mathrm{S}, 19 \div 12^{\prime} \mathrm{E}$ & Simaika and Samways (2008) \\
\hline D & 11 & 37 & 18 & 46 & 164 & 124 & $33 \div 25^{\prime} S, 19 \circ 17^{\prime} E$ & Samways and Grant (2006b) \\
\hline $\mathrm{E}$ & 8 & 22 & 18 & 51 & 225 & 232 & $33 \div 24^{\prime} \mathrm{S}, 19 \div 17^{\prime} \mathrm{E}$ & Samways and Grant (2006b) \\
\hline $\mathrm{F}$ & 5 & 7 & 11 & 15 & 220 & 214 & $33 \div 50^{\prime} S, 22 \div 26^{\prime} E$ & Samways and Grant (2006b) \\
\hline G & 4 & 9 & 8 & 22 & 200 & 244 & $3349^{\prime} \mathrm{S}, 23500^{\prime} \mathrm{E}$ & Samways and Grant (2006b) \\
\hline $\mathrm{H}$ & 5 & 11 & 11 & 36 & 220 & 327 & $32 \div 36^{\prime} S, 27 \div 25^{\prime} E$ & Samways and Grant (2006b) \\
\hline I & 7 & 10 & 9 & 21 & 129 & 210 & $24 \div 53^{\prime} S, 30 \div 45^{\prime} E$ & Samways and Grant (2006b) \\
\hline $\mathrm{J}$ & 13 & 22 & 20 & 25 & 154 & 114 & $22 \div 50^{\prime} S, 30 \div 36^{\prime} \mathrm{E}$ & Magoba and Samways (2009) \\
\hline
\end{tabular}

This recovery is expressed as a change in both percentage of species richness (Species Recovery Score) and in percentage DBI (Dragonfly Recovery Score). Scores are based on raw data on dragonfly species changes over time in published works 


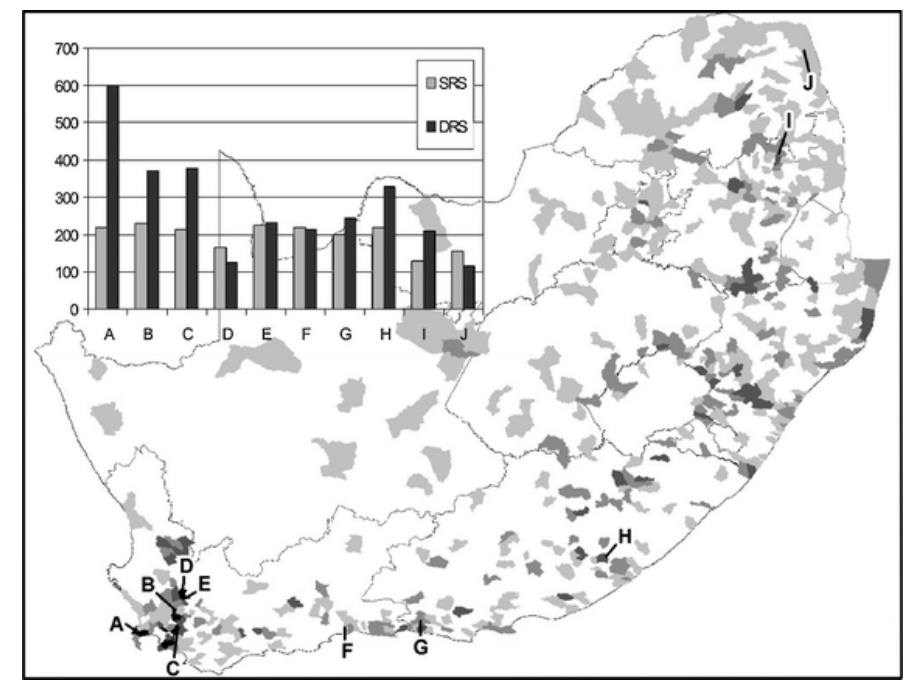

Fig. 7

Percent recovery of dragonfly fauna at sites (A-J) following removal of alien invasive riparian trees, expressed as percent Species Recovery Score (SRS) and Dragonfly Recovery Score (DRS). Source data for sites A-J are given in Table 3. The recovery scores are overlaid on a map of South Africa, showing the number of national endemic dragonfly species across South Africa, at the quaternary catchment scale. Light gray catchments show low levels of endemism, black ones high levels of endemism

In terms of global prioritization of habitat conservation, the DBI is more readily applied than the AvTD. Conservation organizations would be interested in the results of the DBI, as the index identifies priority sites for conservation action of highly threatened and sensitive species. The AvTD can also be used to identify areas of conservation concern, but more readily at a national level. For example, different provinces of South Africa may want to conserve their own hotspots of biodiversity, in a regional context, that takes species representativeness into account.

\section{Use of the Dragonfly Biotic Index for environmental monitoring}

The use of the DBI and AvTD has been suggested for environmental monitoring (Simaika and Samways 2008a; Warwick and Clarke 1995). The AvTD has already been applied to tracking habitat disturbance (e.g. Clarke and Warwick 1998; Mouillot 2005), while the DBI has been employed for assessing the success of stream restoration through removal of invasive alien trees, a key threat to various aquatic organisms (Samways and Taylor 2004).

Application of the DBI to tracking habitat recovery, from alien riparian plant invasion, is termed here the DRS, which is the total DBI after restoration compared with the value before restoration. The results (Table 3; Fig. 7) are clear, with restoration resulting an increase in both species richness (the SRS) and the total DBI (DRS) at all the sites. However, the added value of the DBI over species richness is that it weights those species which are geographically restricted, threatened and sensitive. The outcome in practical terms is that the restoration activities were highly beneficial not just to the common, widespread generalists but noticeably also to the irreplaceable, narrow-range endemics. Thus, the DBI is a very effective method for monitoring river remediation, especially for those species of conservation concern.

In terms of practicality, the individual DBIs for all species, with a description and other essential species information is given in Samways (2008). This information is therefore readily available to managers without them having to undertake any individual species assessments. This 'canned' 
information is simply ready to plug into the total DBI calculations (and the DRS), which makes it easy to use. The DBI has the added advantage that species can be easily and rapidly identified, and habitats scored while in the field. Thus for local rapid environmental impact assessments and habitat monitoring schemes, the DBI is a low-cost, easy-to-use alternative. We therefore recommend the use and integration of the $\mathrm{DBI}$ into management and conservation schemes.

Previous work has shown a strong correlation between adult dragonfly scores and macroinvertebrate scores (Smith et al. 2007). This suggests that the DBI, as a measure of ecological integrity, could be used alongside macroinvertebrate scores (Dickens and Graham 2002) for freshwater health assessments. However, the exact relationship between the DBI and macroinvertebrate scores requires further, detailed exploration.

Despite the obvious and very positive advantages of the indices presented here, it must be mentioned that all the various elements of biodiversity cannot be encapsulated within a single index (Warwick and Clarke 1995; Price et al. 1999). Furthermore, species presence-absence data, whether using taxonomic distinctness or a combined index based on geographic distribution, threat and sensitivity, are not the only facets of diversity. The distribution of individuals among species (evenness), for example, is another very important element (Price et al. 1999) and the particular abundances of species may be important for maintaining significant functions and services (Luck et al. 2003). Finally, study of a single taxon, including odonates, should not be taken simply at face value to represent overall biodiversity (Price et al. 1999; Oertli 2008), a situation easily remedied by concordance studies with other taxa.

\section{Practicality and general applicability of the Dragonfly Biotic Index}

The DBI requires a good record of dragonfly species in an area under investigation (e.g. $100 \mathrm{~m}$ stretch of stream, subsection of marshland or portion of catchment). As found elsewhere, five site visits with slow walking of the banks is usually sufficient (Schmidt 1985). It is at times necessary to supplement this activity with searches of dense vegetation for crepuscular species (for example Gynacantha and Zyxomma species). The only equipment required is an aerial net for confirmation of species identity, and a 10X $+20 \mathrm{X}$ hand lens for close examination of diagnostic characters (e.g. genitalia). A good field guide of the local odonate fauna, its habitat tolerance, geographical distribution and some indication of level of threat is also necessary. When more knowledge becomes available, this can be built into a field guide, as has been done for South African dragonflies (Samways 2008). Thus the method initially will have some challenges where the dragonfly fauna is poorly known. However, it is not out of the question to establish some preliminary values for individual species DBIs, refining them as more information becomes available. Also, there needs to be some knowledge of the flight periods to ensure all species are accounted for (Samways and Grant 2006a, b).

Employing the DBI will inevitably bring upon itself the criticism that adults may not represent the larvae, and larvae should also be used in the index. This can be countered on various points. Firstly, a comparable sample of larvae requires far more sampling effort, because sampling in water is awkward and larvae can be very cryptic and live in inaccessible places (Niba and Samways 2006a). Secondly, if a good sample is obtained, only final-instar larvae can be identified to species level. Thirdly, in many countries, including South Africa, a large proportion of dragonfly larvae remain yet to be described, and their identification requires more effort than that of adults. Fourth, adults typically mate and oviposit only in suitable freshwater habitats, thus residency of most species collected in mating habitat can be assumed. Should there still be skeptics, one could argue that the only true record of residency is not the larvae but the exuviae, left behind after emergence (Ott et al. 
2007). This is the only true demonstration that the habitat in question is suitable to odonates in both the aquatic and aerial parts of the life cycle.

The total DBI records the 'core resident species' (Niba and Samways 2006b). Some vagrant species will of course also be recorded, particularly when more intensive searches over longer periods of time are done. The occasional, additional records, however, tend not to affect the total DBI to any great extent. Thus, the overall score of the DBI is the contribution by core resident species.

While we have presented the results here for one country, the concept of the DBI could be easily adapted elsewhere. However, this depends on the number of species in the odonate fauna, its breadth of geographic distribution, Red List status and sensitivity to disturbance. Where more or alternate information is available, the index could be expanded to include sub-indices such as habitat tolerance and relative abundance. The limit to the DBI is that odonates may not be good surrogate species for other taxa, owing to lack of concordance (Prendergast et al. 1993), although they have potential use as umbrellas for wetland plant species (Bried et al. 2007). Nevertheless, the easy use of the $\mathrm{DBI}$ and the sensitivity of the index mean that it is a useful tool towards conservation action.

Acknowledgments

We would like to thank René Gaigher, who assisted with data entry and database management. We are also grateful to Jesse Kalwij and Aruna Manrakhan for comment on an early draft of the manuscript, and two anonymous referees for their valuable insight. Bob Clarke (Primer-E Ltd) provided statistical advice. This is a contribution to the EU/ALARM Assessing Large Scale Environmental Risks for Biodiversity with Tested Methods), Project No. GOCE-CT-2003-506775.

\section{References}

Bried JT, Herman BD, Ervin GN (2007) Umbrella potential of plants and dragonflies for wetland conservation: a quantitative case study using the umbrella index. J Appl Ecol 44:833842.

Chovanec A (2000) Dragonflies (Insecta: Odonata) as indicators of the ecological integrity of aquatic systems-a new assessment approach. Verh Int Verein Limnol 27:887-890

Chovanec A, Waringer J (2001) Ecological integrity of river-floodplain systems-assessment by dragonfly surveys (Insecta: Odonata). Regul Rivers Res Manage 17:493-507.

Clarke KR, Warwick RM (1998) A taxonomic distinctness index and its statistical properties. J Appl Ecol 35:523-531.

Clarke KR, Warwick RM (2001) Change in marine communities: an approach to statistical analysis and interpretation, 2nd edn. PRIMER-E, Plymouth

Dickens CWS, Graham PM (2002) The South African Scoring System (SASS) version 5 rapid bioassessment method for rivers. Afr J Aquat Sci 27:1-10

Dijkstra K-DB, Samways MJ, Simaika JP (2007) Two new relict Syncordulia species found during museum and field studies of threatened dragonflies in the Cape Floristic Region (Odonata: Corduliidae). Zootaxa 1467:19-34 
Dinerstein E, Wikramanayake ED (1993) Beyond "hotspots": how to prioritize investments to conserve biodiversity in the Indo-Pacific region. Conserv Biol 7:53-65.

Ellingsen KE, Clarke KR, Somerfield PJ, Warwick RM (2005) Taxonomic distinctness as a measure of diversity applied over a large scale: the benthos of the Norwegian continental shelf. J Anim Ecol 74:1069-1079.

Environmental Survey Research Institute (ESRI) (1999) ArcView 3.2a. http.esri.com

Environmental Survey Research Institute (ESRI) (2006) ArcGIS 9.2. http.esri.com

Fleishman E, Noss RF, Noon BR (2006) Utility and limitations of species richness metrics for conservation planning. Ecol Indic 6:543-553.

Graham CH, Hijmans RJ (2006) A comparison of methods for mapping species ranges and species richness. Glob Ecol Biogeogr 15:578-587.

Heino J, Mykrä H, Hämäläinen H, Aroviita J, Muotka T (2007) Responses of taxonomic distinctness and species diversity indices to anthropogenic impacts and natural environmental gradients in stream macroinvertebrates. Freshw Biol 52:1846-1861.

International Union for Conservation of Nature and Natural Resources (IUCN) (2001) IUCN Red List Categories and Criteria: Version 3.1. IUCN SSC Species Survival Commission, IUCN, Gland Switzerland

Jennings MD, Hoekstra J, Higgins J, Boucher T (2008) A comparative measure of biodiversity based on species composition. Biodivers Conserv 17:833-840.

Lamoreux JF, Morrison JC, Ricketts TH, Olson DM, Dinerstein E, McKnight MW et al (2006) Global tests of biodiversity concordance and the importance of endemism. Nature 440:212-214.

Luck GW, Daily GC, Ehrlich PR (2003) Population diversity and ecosystem services. Trends Ecol Evol 18:331-336.

Magoba RN, Samways MJ (2009) Restoration of aquatic macroinvertebrate assemblages through large-scale removal of invasive alien trees. In preparation

Magurran AE (2004) Measuring biological diversity. Blackwell, Oxford

McGeoch MA (2007) Insects and bioindication: theory and progress. In: Stewart AJA, New TR, Lewis OT (eds) Insect conservation biology. CABI, Wallingford, pp 144-174

Midgley DC, Pitman WV, Middleton BJ (1994) Surface water resources of South Africa 1990: WRC report no. 298/1/94. Water. Resource Commission, Pretoria, South Africa

Mouillot D, Gaillard S, Aliaume C, Verlaque M, Belsher T, Troussellier M et al (2005) Ability of taxonomic diversity indices to discriminate coastal lagoon environments based on macrophyte communities. Ecol Indic 5:1-17. 
Niba AS, Samways MJ (2006a) Remarkable elevational tolerance in an African dragonfly (Odonata) assemblage. Odonatologica 35:265-280

Niba AS, Samways MJ (2006b) Development of the concept of 'core resident species' for quality assurance of an insect reserve. Biol Conserv 15:4181-4196

Oertli B (2008) The use of dragonflies in the assessment and monitoring of aquatic habitats. In: Córdoba-Aguilar A (ed) Dragonflies: model organisms for ecological and evolutionary research. Oxford University Press, Oxford

Orme CDL, Davies RG, Burgess M, Eigenbrod F, Pickup N, Olson VA et al (2005) Global hotspots of species richness are not congruent with endemism or threat. Nature 436:10161019.

Ott J (2008) Dragonflies and climate change. Pensoft, Sofia

Ott J, Schorr M, Trockur B, Lingenfelder U (2007) Species protection programme for the Orange-spotted emerald (Oxygastra curtisii, Insecta: Odonata) in Germany - the example of the River Our population. Insect Ecology and Conservation Monographs, Pensoft, Bulgaria

Pinhey E (1984) A survey of the dragonflies (Odonata) of South Africa. Part 1. Zygoptera. J Entomol Soc S Afr 47:147-188

Pinhey E (1985) A survey of the dragonflies (Odonata) of South Africa. Part 2. Anisoptera. J Entomol Soc S Afr 48:1-48

Prendergast JR, Quinn RM, Lawton JH, Eversham BC, Gibbons DW (1993) Rare species, the coincidence of diversity hotspots and conservation strategies. Nature 365:335-337.

Pressey RL, Humphries CJ, Margules CR, Vane-Wright RI, Williams PH (1993) Beyond opportunism: key principles for systematic reserve selection. Trends Ecol Evol 8:124-128.

Price ARG, Keeling MJ, O’Callaghan CJ (1999) Ocean-scale patterns of 'biodiversity' of Atlantic asteroids determined from taxonomic distinctness and other measures. Biol J Linn Soc Lond 66:187-203

Samways MJ (2008) Dragonflies and damselflies of South Africa. Pensoft, Sofia

Samways MJ, Grant PBC (2006a) Honing Red List assessments of lesser-known taxa in biodiversity hotspots. Biol Conserv 16:2575-2586

Samways MJ, Grant PBC (2006b) Regional response of Odonata to river systems impacted and cleared of invasive alien trees. Odonatologica 35:297-303

Samways MJ, Taylor S (2004) Impacts of invasive alien plants on red-listed South African dragonflies (Odonata). S Afr J Sci 100:78-80

Schmidt E (1985) Habitat linearization, characterization and bioindication by a 'Representative Spectrum of Odonata Species (RSO). Odonatologica 14:127-133

Schulze RE, Hallowes LA, Horan MJC, Lumsden TG, Pike A, Thornton-Dibb S et al. (2006) South African quaternary catchments database. In: Schulze RE (ed) South African atlas of 
climatology and agrohydrology. Water Research Commission, Pretoria, RSA, WRC Report 1489/1/06, Sect. 2.3

Simaika JP, Samways MJ (2008a) Valuing dragonflies as service providers. In: CórdobaAguilar A (ed) Dragonflies: model organisms for ecological, evolutionary research. Oxford University Press, Oxford, pp 109-123

Simaika JP, Samways MJ (2008b) Description of final instar larvae of Ecchlorolestes Sélys (Zygoptera: Synlestidae) from South Africa. In preparation

Smith J, Samways MJ, Taylor S (2007) Assessing riparian quality using two complementary sets of bioindicators. Biol Conserv 16:2695-2713

South African National Botanical Institute (SANBI) Biodiversity GIS Unit http://bgis.sanbi.org. Last visited: February 2008

SPSS Inc (2004) SPSS version 13.0 for windows. SPSS Inc, Chicago

Virolainen KM, Suomi T, Suhonen J, Kuitenen M (1998) Conservation of vascular plants in single large and several small mires: species richness, rarity and taxonomic diversity. J Appl Ecol 35:700-707

Warwick RM, Clarke KR (1995) New 'biodiversity’ measures reveal a decrease in taxonomic distinctness with increasing stress. Mar Ecol Prog Ser 129:301-305.

Warwick RM, Clarke KR (2001) Practical measures of marine biodiversity based on relatedness of species. Oceanogr Mar Biol Ann Rev 39:207-231

Wilkinson DM (1999) The disturbing history of intermediate disturbance. Oikos 84:145-147. 